\title{
Optimization of a Batch Reactor for Biomass-derived Renewable Polyesters
}

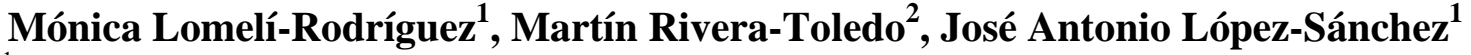 \\ ${ }^{1}$ Stephenson Institute for Renewable Energy, Department of Chemistry, University of Liverpool \\ Crown Street, Liverpool, L69 7ZD UK \\ mlomeli@liv.ac.uk; jals@liv.ac.uk \\ ${ }^{2}$ Departamento de Ingeniería y Ciencias Químicas, Universidad Iberoamericana \\ Prolongación Paseo de la Reforma 880, Ciudad de México, 01219 México \\ martin.rivera@ibero.mx
}

\begin{abstract}
For the first time, we present the process simulation and multiobjective optimization of the batch reactor polyesterification of a library of biomass-derived renewable polyesters: poly(1,3-propylene succinate) (PPS), and poly(1,3-propylene 2,5furandicarboxylate-co-1,3-propylene succinate) (PPFPS). The simulation environment was implemented in Aspen Plus ${ }^{\mathrm{TM}}$ and the $\varepsilon^{-}$ constraint method was followed for the multi-optimization problem, considering two objective functions that maximize the number degree of polymerization (DPN) and minimize the heat duty $Q$ of the reactor. The efficient operation points are reported for each case through the construction of Pareto frontiers and the performance of the biobased polyesters was compared to that of petroderived polyethylene teraphthalate (PET) in terms of sustainability indicators and final polymer attributes, such as number molecular weight $\left(\mathrm{M}_{\mathrm{n}}\right)$, and number degree of polymerization (DPN). The kinetic rate expressions were defined following the functional group approach for step-growth kinetics and the parameters were estimated by fitting a polyesterification model found in the literature to the experimental data. The present work provides comprehensive fundamentals towards a feasible process simulation, process design and scale up of the polyesterification of biomass-derived products.
\end{abstract}

Keywords: Biomass, polyesters, process simulation, multi-objective optimization, kinetics

\section{Introduction}

Lately, lignocellulosic biomass sources have become important to lower the dependence of industry on traditional fossil feedstocks. The biorefinery concept arises as a potential and necessary alternative to supply a portfolio of products, including monomers for polymer synthesis. Within polymers, polyesters are an exciting field for the inclusion of biobuilding blocks due to their extended applications. We have recently reported the synthesis and kinetic modelling of renewable polyesters based on 2,5-furan dicarboxylic acid (FDCA), succinic acid (SA) and 1,3-propanediol (PDO).[1] As continuous research has been pursued in the synthesis of biomass-derived polyesters, it is imperative to properly scale up the production processes so these are feasible from a sustainable and economical perspective. Therefore, the implementation of a range of process engineering tools, such as modeling, sensitivity analysis, and optimization would allow the determination of the best operation conditions for the production of these polymers, ensuring a proper molecular weight and narrow molecular weight distributions (MWD).[2] Along with the final quality of the synthesised polymers, reduction of production costs needs to be simultaneously considered as well. In this scope, multiobjective optimization (MOO) techniques can be employed when working with simultaneous and opposing performance objectives commonly found in polymerization reactions. This methodology is based upon finding a set of equally good solutions, known as Pareto optimal solutions.[3] In the present work, we report a process engineering study for the batch synthesis of the biomass-derived polyesters poly(1,3-propylene succinate) (PPS) and poly(1,3-propylene 2,5-furandicarboxylate-co-1,3propylene succinate (PPFPS). Firstly, the reaction modeling covers the estimation of kinetic parameters by fitting a predetermined polyesterification model to the experimental data. Next, the batch process simulation and MOO were performed in Aspen Plus ${ }^{\mathrm{TM}}$, concluding with the assessment of sustainability indicators for each case. The analysis for PET 
has been included as a comparative petro-derived polyester reference. We focus solely on the chemical synthesis reactor since it is considered the core of any process.

\section{Methodology}

\subsection{Synthesis of Biomass-Derived Polyesters}

The polyesters were synthesized from 2,5-furan dicarboxylic acid (FDCA), 1,3-propanediol (PDO) and succinic acid (SA) in a four-neck round bottom flask $(250 \mathrm{~mL})$ or a single wall glass reactor $(500 \mathrm{~mL})$ by a two-step process comprising polyesterification and azeotropic distillation with xylene. The complete experimental procedure can be found in our previous work.[1] The structures of the biomass-derived polyesters are shown in Figure 1 and the concentrations of the monomers are summarized in Table 1.

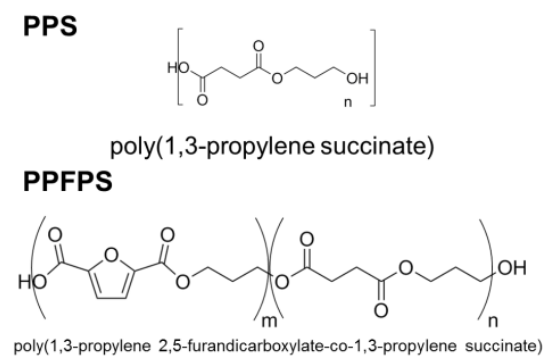

Fig. 1: Chemical structures of the biomass derived polyesters.

Table 1: Composition of synthesized polyesters.

\begin{tabular}{|c|c|c|c|}
\hline Polyester & $\begin{array}{c}\text { Molar ratio } \\
\text { diol:diacid }\end{array}$ & $\begin{array}{c}\text { FDCA } \\
\text { mol\% }\end{array}$ & $\begin{array}{c}\text { SA } \\
\text { mol\% }\end{array}$ \\
\hline PPS & 1.1 & 0 & 100 \\
\hline PPFPS 15/85 & 1.5 & 15 & 85 \\
\hline PPFPS 70/30 & 1.5 & 70 & 30 \\
\hline PPFPS 85/15 & 1.5 & 85 & 15 \\
\hline
\end{tabular}

\subsection{Development of Kinetic Model}

For the simulation in Aspen Plus ${ }^{\mathrm{TM}}$, we considered the functional group approach and followed the procedure used by Seavey et al.[4] for PET. Firstly, the main species and segments are defined. The conventional species considered are water, PDO, SA, and FDCA. The diol and diacids polymerize to form the corresponding polyesters, which are composed of terminal (T-) and bound (B-) segments for both the diacids and the diols, as shown in Figure 2. As in the case of PET, two main reactions are considered: esterification or water formation and transesterification. The assumptions considered were equal reactivity hypothesis; [5] the rate coefficients $k_{i}$ of the species are equal to those of the segments; and reversible reactions are disregarded. With the assumptions and species defined, Aspen Plus ${ }^{\mathrm{TM}}$ automatically generates a set of 12 reactions for homopolyesters and 24 for the PPPFS copolyesters. In order to estimate the reaction coefficients $k_{i}$, a polyesterification model from the literature was fitted to the experimental carboxylic acid data, which is calculated from the experimental acid value.[1] This model was proposed by Lehtonen,[6] and was considered because the kinetic parameters included in the ordinary differential equation were the ones required by Aspen Plus ${ }^{\mathrm{TM}}$ for the step-growth polymerization. The rate equation is then defined as Eq. (1):

$$
r=k_{o} e^{\frac{-E_{a}}{R T}}\left(C_{C O O H} C_{O H}-\frac{C_{C O O R} \cdot C_{H_{2} O}}{K}\right)
$$

Where $k_{o}$ is the pre-exponential factor in $\mathrm{kg} \cdot \mathrm{mol}^{-1} \mathrm{~min}^{-1} ; E_{a}$ is the activation energy in $\mathrm{J} \cdot \mathrm{mol}^{-1} ; R$ is the universal gas constant in $\mathrm{J} \cdot \mathrm{mol}^{-1} \mathrm{~K}^{-1} ; K$ is the equilibrium constant; $C_{\mathrm{COOH}}, C_{\mathrm{OH}}, C_{\mathrm{H} 2 \mathrm{O}}$ and $C_{\mathrm{COOR}}$ are the concentrations of 
carboxylic acid, hydroxyl, water and ester, respectively, in mol $\cdot \mathrm{kg}^{-1}$. Figure 3 shows that the experimental conversion is satisfactorily fitted to the esterification model throughout the entire reaction time

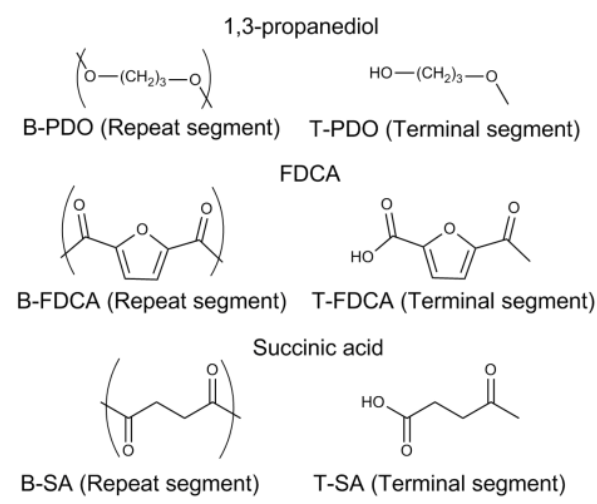

Fig. 2: Chemical structures of the repeat and terminal segments.

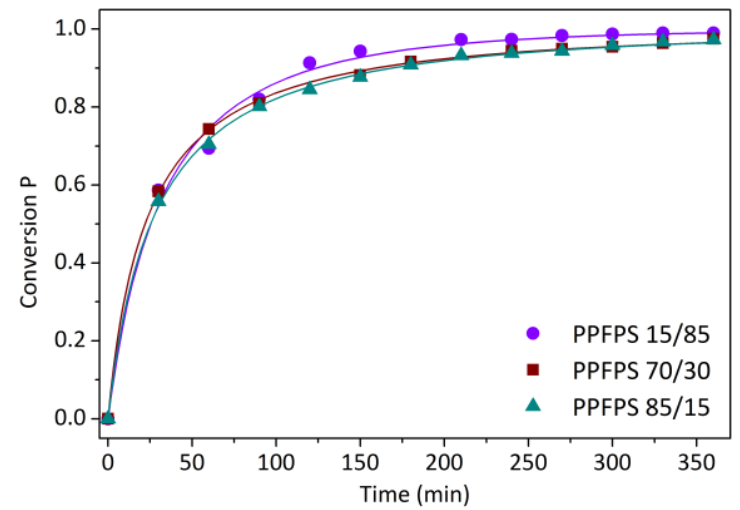

Fig. 3: Conversion of $\mathrm{COOH}$ groups, fitted to the model.

\subsection{Simulation and Multiobjective-Optimization}

The two objective functions $\square_{\square} \square$ and $\square_{\square} \square$ considered for the batch biomass-derived polyesterification refer to both the polymer quality and the costs of production derived from energy usage as defined by equations 2 and 3 below:

$$
\begin{gathered}
\psi_{1}=\max (D P N) \\
\psi_{2}=\min (Q)
\end{gathered}
$$

Where $D P N$ is the number degree of polymerization and $Q$ is the heat duty in $\mathrm{kBTU} \cdot \mathrm{h}^{-1}$.

\subsection{Sustainability Indicators}

The simulations were assessed thus according to environmental, energy and economic bases in terms of common sustainability indicators for chemical processes.[7] We considered two indicators: Specific energy intensity ( $\left.\mathrm{R}_{\mathrm{SEI}}\right)$ and global warming potential (GWP), which refer to the net energy used as primary fuel and total mass of $\mathrm{CO}_{2}$ equivalents per mass of final polyester, respectively. The worst case scenarios for the indicators refer to $\mathrm{R}_{\mathrm{SEI}}$ of $1.95 \times 10^{3} \mathrm{MJ} \cdot \mathrm{kg}^{-1} \mathrm{and}$ all GWP released. The estimation of the sustainability indicators after the optimization was done considering natural gas as base fuel under the Environmental Protection Agency (EPA) rule E9-5711, included in the Aspen Plus ${ }^{\mathrm{TM}}$ interface. 


\section{Results and Discussion}

\subsection{Simulation and Multiobjective Optimization (MOO)}

The batch simulation and $\square$-constraint optimization performed in Aspen Plus ${ }^{\mathrm{TM}}$ for the different polyesters provided the optimum operation conditions and the results of the mass balances for each of the monomers, segments concentration profiles, energy balances, and polymer attributes such as number molecular weight $M_{n}$ and DPN. We considered a production of $40 \mathrm{t} \cdot \mathrm{d}^{-1}$ as the base case. The Polymer Non-Random Two Liquid (PolyNRTL) activity coefficient method was used for the thermodynamic properties coupled with the Van Kravelen group contribution method.[8] The molecular weight of most polyesters used in coatings range between 2 and $6 \mathrm{kDa}$.[9] Table 2 summarizes the efficient or compromise solutions obtained from the MOO as well as the sustainability indicators considered. The GWP results are normalized from 0 to $100 \%$ sustainability. The Pareto frontier for PPS is depicted in Figure $4 \mathrm{a}$, whereas the $\mathrm{M}_{\mathrm{n}} / \mathrm{DPN}$ and segment concentration profiles are shown for PPFPS 70/30 (Figure 4b) and PPFPS 15/85 (Figure 4c), respectively. All the optimum process temperatures of our polyesters were in the range of $191-220{ }^{\circ} \mathrm{C}$, while PET is processed well above that range, at $269{ }^{\circ} \mathrm{C}$, which falls within the operating conditions found in the literature.[4] The simulated final $\mathrm{M}_{\mathrm{n}}$ and DPN were around $4.2 \mathrm{kDa}$ and 40 , respectively, suitable for coil coatings. The polymeric attributes for PET were lower, with a final $\mathrm{M}_{\mathrm{n}}$ of $3.6 \mathrm{kDa}$ and degree of polymerization of 38 . In terms of heat duty, although the energy consumption is similar between PET and our polyesters, the main advantage relies in terms of the sustainability indicators. They suggested that the production of PPFPS 70/30 releases less $\mathrm{CO}_{2}$ among all polyesters, as its normalized GWP is $91 \%$ of sustainability, although PPFPS $15 / 85$ is the most energyefficient process, as the specific energy intensity is $1.60 \mathrm{MJ} \cdot \mathrm{kg}^{-1}$. The production of PET presented the highest energy consumption and $\mathrm{CO}_{2}$ release among all the polymers studied $\left(1.90 \mathrm{MJ} \cdot \mathrm{kg}^{-1}\right.$ and $88 \%$, respectively) suggesting that our polyesters would be a sustainable and efficient alternative to conventional PET for the intended application.

Table 2: Composition of synthesized polyesters.

\begin{tabular}{|c|c|c|c|c|c|c|c|c|}
\hline Polyester & $\begin{array}{c}\text { Temperature, } \\
{ }^{\circ} \mathrm{C} \\
\end{array}$ & $\begin{array}{l}M_{n,} \\
\text { kDa }\end{array}$ & DPN & $\begin{array}{c}\text { Polymer, } \\
\text { kg } \cdot \mathrm{hr}^{-1}\end{array}$ & $\begin{array}{c}\text { Heat Duty, } \\
\text { MJ.hr }{ }^{-1}\end{array}$ & $\begin{array}{c}\text { GWP, } \\
\text { Normalized }\end{array}$ & $\begin{array}{c}\mathbf{R}_{\text {SEI }} \\
\mathbf{M J} \cdot \mathbf{k g}_{\text {polymer }}^{-1} \\
\end{array}$ & $\begin{array}{c}\mathbf{R}_{\mathrm{SEI}} \\
\text { Normalized } \\
\end{array}$ \\
\hline PPS & 191 & 4.2 & 43 & 1360 & 2200 & 0.89 & 1.80 & 0.092 \\
\hline PPFPS $15 / 85$ & 212 & 4.2 & 43 & 1400 & 2200 & 0.90 & 1.60 & 0.082 \\
\hline PPFPS 70/30 & 220 & 4.0 & 43 & 1400 & 2200 & 0.91 & 1.70 & 0.087 \\
\hline PPFPS 85/15 & 215 & 4.0 & 42 & 1400 & 2300 & 0.90 & 1.70 & 0.087 \\
\hline PET & 269 & 3.6 & 38 & 1280 & 2400 & 0.88 & 1.90 & 0.097 \\
\hline
\end{tabular}

\section{Conclusions}

The process simulation and optimization were successfully implemented in Aspen Plus ${ }^{\mathrm{TM}}$ for the polyesterification of biomass-derived monomers FDCA, succinic acid and 1,3-propanediol. The kinetic parameters $E_{a}, k_{o}$, and $K$ were estimated in Matlab ${ }^{\mathrm{TM}}$ for each polyester system by fitting the experimental batch data to a polyesterification model proposed in the literature and regressing the data using the weighting sum squares method. The $a$ posteriori optimization $\square$-constraint method was followed to determine the utopia points and compromise solutions.

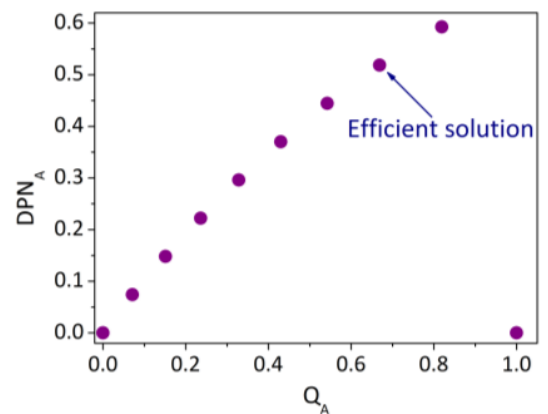

a)

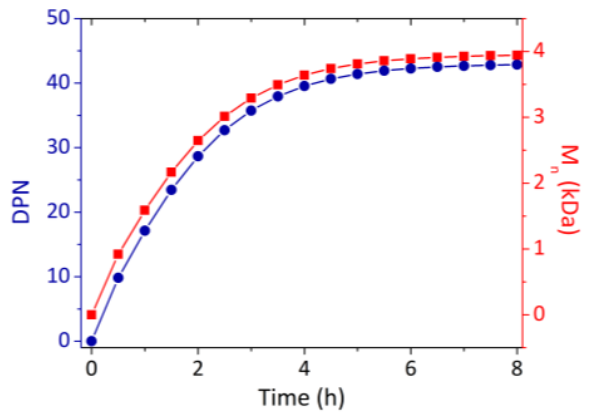

b)

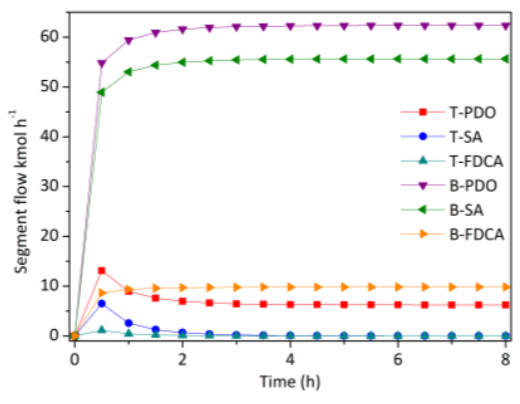

c)

Fig. 4: a) Pareto frontier for PPS. b) DPN and Mn profiles for PPFPS 70/30. c) Segment flow profiles for PPFPS 15/85. 
The optimum process temperatures were in the range of $191{ }^{\circ} \mathrm{C}$ to $215^{\circ} \mathrm{C}$ whereas the processing temperature for PET was $269^{\circ} \mathrm{C}$. The number molecular weight $\mathrm{M}_{\mathrm{n}}$ and degree of polymerization DPN of the polyesters were in the range of 4.0 and $4.2 \mathrm{kDa}$ and 42-43, respectively, suitable for coating resins. The final production of about $1400 \mathrm{~kg}_{\text {polymer }} \cdot \mathrm{h}^{-1}$. PET targeted lower polymer quality, with $\mathrm{M}_{\mathrm{n}}$ of $3.6 \mathrm{kDa}$ and DPN of 38 . The environmental impact of the processes was addressed by the principles of sustainability performance indicators, which showed that PET production releases $\mathrm{more}^{\mathrm{CO}} \mathrm{O}_{2}$ and is the least energy efficient of the production processes. The present process engineering study for this biomassderived family of polyesters provides and insightful and useful source for further polymerization process design and implementation stages. Different reactor configurations and biomass-derived polyesterification systems will be evaluated in the future.

\section{Acknowledgements}

The authors acknowledge the EPSRC (Grant EP/K014773/1) for funding support. We would also like to thank Dr. Thomas E. Davies from University of Cardiff for his valuable support. Mónica Lomelí-Rodríguez is grateful to Consejo Nacional de Ciencia y Tecnología (CONACYT) for funding support.

\section{References}

[1] M. Lomelí-Rodríguez, M. Martín-Molina, M. Jiménez-Pardo, Z. Nasim-Afzal, S. I. Cauët, T. E. Davies, et al., "Synthesis and kinetic modeling of biomass-derived renewable polyesters," Journal of Polymer Science Part A: Polymer Chemistry, vol. 54, pp. 2876-2887, 2016.

[2] S. Garg and S. K. Gupta, "Multiobjective optimization of a free radical bulk polymerization reactor using genetic algorithm," Macromolecular Theory and Simulations, vol. 8, pp. 46-53, 1999.

[3] M. Rivera-Toledo and A. Flores-Tlacuahuac, "A Multiobjective Dynamic Optimization Approach for a MethylMethacrylate Plastic Sheet Reactor," Macromolecular Reaction Engineering, vol. 8, pp. 358-373, 2014.

[4] K. Seavey and Y. A. Liu, Step-growth polymerization process modeling and product design. John Wiley \& Sons, 2009.

[5] S. K. Gupta and A. Kumar, Reaction engineering of step growth polymerization. Springer Science \& Business Media, 2012.

[6] J. Lehtonen, T. Salmi, K. Immonen, E. Paatero, and P. Nyholm, "Kinetic model for the homogeneously catalyzed polyesterification of dicarboxylic acids with diols," Industrial \& engineering chemistry research, vol. 35, pp. 39513963, 1996.

[7] G. J. Ruiz-Mercado, R. L. Smith, and M. A. Gonzalez, "Sustainability indicators for chemical processes: I. Taxonomy," Industrial \& Engineering Chemistry Research, vol. 51, pp. 2309-2328, 2012.

[8] D. W. Van Krevelen Properties of polymers: their correlation with chemical structure; their numerical estimation and prediction from additive group contributions. Elsevier, 2009.

[9] E. Gubbels, L. Jasinska-Walc, B. A. Noordover, and C. E. Koning, "Linear and branched polyester resins based on dimethyl-2, 5-furandicarboxylate for coating applications," European Polymer Journal, vol. 49, pp. 3188-3198, 2013. 